\title{
ANALISIS EFISIENSI ASURANSI UMUM SYARIAH DI INDONESIA TAHUN 2013-2015: APLIKASI METODE DATA ENVELOPMENT ANALYSIS (DEA)'
}

Yulia Wahyu Ningsih

Mahasiswa Program Studi S1 Ekonomi Islam-Fakultas Ekonomi dan Bisnis-Universitas Airlangga Email: yulia.wahyu-13@feb.unair.ac.id

Noven Suprayogi

Departemen Ekonomi Syariah-Fakultas Ekonomi dan Bisnis - Universitas Airlangga

Email: noven.suprayogi@feb.unair.ac.id

\begin{abstract}
:
This study aims to analyze the efficiency of sharia general insurance companies in Indonesia. The input variables used are total assets, expenses, and payment of claims, while the output variable is the income and tabarru' funds. The method were used to measure the level of efficiency is the Data Envelopment Analysis (DEA) with the assumption of Variable Return to Scale (VRS) with input and output orientation. The samples are 12 sharia general insurance companies during 2013-2015. The results of the study indicate that the average result of DEA analysis for the entire DMU (Decision Making Unit) has not been efficient. The average value of economic efficiency (CRS) by 0.978 , technically efficiency (VRS) for 0.925 , and scale efficiency for 0.945. Source of inefficiency sharia insurance company is the scale of operations and management of input to output is not optimal.
\end{abstract}

Keywords: Efficiency, Sharia General Insurance, DEA, VRS

\section{PENDAHULUAN}

\section{Latar Belakang}

Asuransi syariah (takaful) merupakan lembaga keuangan non bank yang mengalami perkembangan cukup pesat. Sejak didirikannya perusahaan asuransi syariah pertama kali pada tahun 1994 melalui PT Syarikat Takaful Indonesia (STI), hingga pada tahun 2015 telah tercatat sebanyak 55 perusahaan (OJK, 2015:1). Asuransi umum syariah merupakan jenis asuransi syariah dengan perkembangan yang paling pesat dibandingkan dengan jenis asuransi syariah yang lain. Pada tahun 2015, terdapat 25 unit usaha asuransi umum syariah dan 3 perusahaan full fledge asuransi umum syariah. Namun demikian, perkembangan perusahaan asuransi syariah ini tidak diikuti oleh peningkatan jumlah pengguna asuransi syariah di Indonesia yang masih sangat kecil, yaitu hanya sebesar 0,095 persen dari jumlah penduduk Indonesia (OJK, 2015).

Asuransi syariah muncul sebab pada dasarnya agama Islam mengakui bahwa kecelakaan, kemalangan, dan kematian merupakan takdir Allah. Kejadian tersebut tidak dapat ditolak, untuk mengurangi risiko yang ditanggung atas kejadian tersebut, manusia diperintahkan membuat perencanaan dalam menghadapi masa depan. Sebagaimana firman Allah dalam Al-Qur'an surat Al-Hasyr ayat 18.

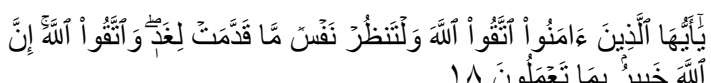

Yā ayyuhal-lażīna "āmanuttaqullāha waltanz̦ur nafsum mā qaddamat li gad, wattaqullāh, „innallāha khabīrum bimā ta"malūn

Artinya: "Hai orang-orang yang beriman, bertakwalah kepada Allah dan hendaklah setiap diri memperhatikan apa yang telah diperbuatnya untuk hari esok (akhirat), dan bertakwalah kepada Allah, sesungguhnya Allah Maha Mengetahui

1 Jurnal ini merupakan bagian dari skripsi yang ditulis oleh Yulia Wahyu Ningsih, NIM : 041311433044 ,

yang diuji pada 19 Januari 2017 
apa yang kamu kerjakan" (Q.S AlHasyr:18) (Departemen Agama Rl, 2005:1121).

Pertumbuhan secara kelembagaan pada asuransi syariah mendorong jumlah aset, investasi, kontribusi bruto, dan klaim bruto semakin tinggi. Berikut ini adalah data jumlah aset, investasi, kontribusi bruto, dan klaim bruto asuransi syariah.

Tabel 1

Pertumbuhan Industri Perasuransian Syariah di Indonesia Tahun 2013-2015 Dalam Trilliun Rupiah

\begin{tabular}{|l|l|l|l|}
\hline \multicolumn{1}{|c|}{ Keterangan } & \multicolumn{1}{c|}{$\mathbf{2 0 1 3}$} & \multicolumn{1}{c|}{$\mathbf{2 0 1 4}$} & $\mathbf{2 0 1 5}$ \\
\hline Kontribusi Bruto & 8,88 & 9,28 & 10,49 \\
\hline Klaim & 2,52 & 2,99 & 3,34 \\
\hline Investasi & 14,30 & 19,46 & 23,07 \\
\hline Aset & 16,66 & 22,36 & 26,52 \\
\hline
\end{tabular}

Sumber: http://www.aasi.or.id/main/databisnis-2015, diakses pada tanggal 05 September 2016, data diolah kembali

Berdasarkan data pada Tabel 1

diatas, pertumbuhan kontribusi dan klaim bruto cenderung melambat dibandingkan dengan pertumbuhan aset dan investasi. Keadaan tersebut disebabkan oleh market share keduanya yang rendah. Market share kontribusi bruto asuransi syariah tahun 2015 sebesar hanya 6,55 persen, untuk asuransi jiwa syariah sebesar 8,60 persen dan asuransi umum syariah sebesar 2,91 persen dibanding total premi asuransi nasional. Kondisi market share kontribusi bruto asuransi umum syariah yang sangat kecil dengan jumlah perusahaan paling banyak dibandingkan dengan jenis perusahaan asuransi syariah yang lain maka persaingan dalam industri asuransi umum syariah semakin ketat. Setiap perusahaan harus mempunyai strategi agar mampu bersaing dengan perusahaan lainnya, salah satunya yaitu dengan menjaga efisiensi yang berarti menyeimbangkan antara beban dan pendapatan agar tidak sampai defisit.

Pertumbuhan kontribusi bruto yang melambat pada perusahaan asuransi syariah di Indonesia kemungkinan juga disebabkan oleh kurang optimalnya pengelolaan dana tabarru'. Karim Consulting Indonesia dalam Islamic Finance Outlook 2015 menyatakan bahwa kinerja perusahaan asuransi syariah dalam mengelola dana tabarru' masih kurang optimal. Pada tahun 2013, terdapat tujuh perusahaan asuransi umum yang mengalami defisit dan hanya enam perusahaan asuransi jiwa syariah yang surplus.

Pembayaran klaim dalam asuransi syariah yang diambilkan dari dana tabarru' menjadikan tersedianya dana tabarru' sebagai faktor penting dalam asuransi syariah. Jika kemungkinan dana tabarru' mengalami defisit (tidak mencukupi untuk pembayaran klaim) maka perusahaan dapat melakukan akad qardh (utang) pada dana perusahaan. Oleh karena itu, disamping harus menjaga ketersediaan dana tabarru' untuk mencukupi kebutuhan klaim peserta, perusahaan asuransi juga harus mampu mengelola dana perusahaan dengan baik. Pengelolaan yang baik pada kedua dana tersebut akan menghasilkan pendapatan bagi perusahaan asuransi syariah untuk tumbuh dan berkembang. 
Abdin dan Endri (2010:21) menyatakan bahwa salah satu aspek penting bagi keberhasilan suatu perusahaan adalah efisiensi. Efisiensi bukan hanya sekadar menekan biaya seminimum mungkin untuk menghasilkan output yang optimal, tetapi mengelola hubungan input dan output sehingga mampu memberikan hasil yang optimal. Pada saat pengukuran efisiensi dilakukan, perusahaan dihadapkan pada kondisi bagaimana mendapatkan tingkat output optimal dengan tingkat input yang ada, atau menggunakan tingkat input minimum untuk tingkat output tertentu.

Efisiensi secara sederhana pada dasarnya menghindari segala bentuk pemborosan. Perusahaan asuransi syariah dapat dikatakan efisien jika mampu menyediakan dana tabarru' untuk membayar kewajiban klaim pada peserta dan meningkatkan pendapatannya untuk tumbuh dan berkembang. Keadaan ini menunjukkan bahwa perusahaan asuransi syariah mampu mengelola kekayaannya dan melakukan proses underwriting yang baik sehingga beban pembayaran klaim dan beban perusahaan mampu dikelola dengan baik. Pengelolaan dana yang baik oleh perusahaan akan tercermin dari jumlah saldo dana tabarru' dan pendapatan perusahaan.

Metode untuk mengukur tingkat efisiensi antara lain analisis rasio, leastsquares regression, total factor productivity, stochastic frontier analysis, dan data envelopment analysis (DEA). Pada penelitian ini menggunakan metode
DEA sebab DEA mampu mengukur efisiensi dengan multiple inputs dan output, tidak perlu mengetahui hubungan antara input dan outputnya, dapat digunakan dengan data input dan output yang berbeda unit, serta hal yang diperbandingkan dapat terlihat secara langsung dari output olahan (Maharani dkk, 2014:2).

Metode DEA merupakan metode non parametrik yaitu sebuah metode optimasi program matematika yang mengukur efisiensi teknik Unit Kegiatan Ekonomi (UKE) atau Decision Making Unit (DMU) dan membandingkan secara relatif terhadap UKE/DMU yang lain (Benarda,dkk., 2016:66). Ada dua model dalam pengukuran DEA yaitu yaitu Variable Return to Scale (VRS) dan Constan Return to Scale (CRS). Lebih lanjut penggunaan DEA, dapat diketahui hal yang menyebabkan perusahaan asuransi umum syariah inefisien. Kemudian, kebijakan apakah yang dapat diambil oleh perusahaan yang inefsien agar mampu mencapai efisiensi dengan mengacu pada perusahaan yang relatif efisien (benchmark). Berkaitan dengan hal tersebut, terdapat dua orientasi pengukuran efisiensi yaitu orientasi input dan orientasi output.

Berdasarkan uraian diatas, maka dengan permasalahan jumlah perusahaan asuransi umum syariah di Indonesia yang lebih banyak dan market share kontribusi bruto yang lebih kecil dibanding perusahaan asuransi syariah lainnya maka pengukuran efisiensi perlu 
dilakukan untuk mengukur kemampuan bertahan perusahaan asuransi umum syariah dalam ketatnya persaingan. Oleh karena itu, rumusan masalah dalam penelitian ini adalah mengukur sejauh mana tingkat efisiensi perusahaan asuransi umum syariah di Indonesia tahun 20132015 dengan metode Data Envelopment Analysis (DEA)?

\section{LANDASAN TEORI}

\section{Konsep Asuransi Syariah}

Menurut Husain Hamid Hisan dalam Rodoni (2015:22), asuransi syariah merupakan kesepakatan kerja sama (ta'awun) antara berbagai pihak dalam mengantisipasi suatu peristiwa. Apabila peristiwa tersebut terjadi, maka semua akan saling bekerja sama untuk menanggungnya. Hal ini sesuai dengan firman Allah pada Surat Al-Maidah ayat 2.

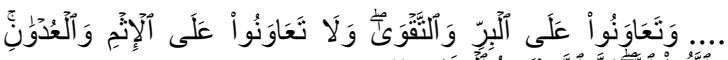

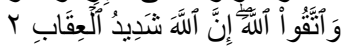
....wa ta'āwanū 'alal birri wat-taqwā, wa lā ta'āwanū 'alal iśmi wal-'udwān, wattaqullāh, innallāha syadīdul 'iqāb

Artinya: ".... dan tolong-menolonglah kamu dalam (mengerjakan) kebajikan dan takwa, dan jangan tolong-menolong dalam berbuat dosa dan pelanggaran. Dan bertaqwalah kamu kepada Allah, sesungguhnya Allah amat berat siksaNya". (Q.S Al-Maidah:2) (Departemen Agama Rl, 2005:200).

Ayat tersebut menjelaskan bahwa Allah memerintahkan kita untuk saling tolong-menolong yang berbentuk Albirru'al-taqwa yakni segala bentuk hal yang membawa kepada kemaslahatan dan ketakwaan, walaupun dengan orang-orang yang tidak seiman dengan kamu (Shihab, 2002:17). Konsep dasar inilah yang mendasari asuransi syariah dan menjadi pokok perbedaan dengan asuransi konvensional.

Berdasarkan Undang-Undang Nomor 40 Tahun 2014 Tentang Perasuransian, menjelaskan jenis usaha asuransi syariah ada tiga yaitu usaha asuransi umum syariah, usaha asuransi jiwa syariah dan usaha reasuransi syariah. Ketiga jenis usaha asuransi syariah tersebut dibedakan atas objek yang diasuransikan.

Berdasarkan Fatwa Dewan Syariah Nasional Majelis Ulama Indonesia Nomor 21/DSN-MUI/X/2001 tentang Pedoman Umum Asuransi Syariah, menjelaskan bahwa akad dalam asuransi syariah terdiri dari dua, yaitu akad tijarah dan akad tabarru'. Akad tijarah adalah semua bentuk akad yang dilakukan untuk tujuan komersial, biasanya adalah akad mudharabah. Akad tabarru' adalah semua bentuk akad yang dilakukan dengan tujuan kebajikan dan tolongmenolong, biasanya akad hibah dana tabarru' antar peserta.

Perusahaan asuransi dalam konsep asuransi syariah hanya bertindak sebagai pengelola dana tabarru' atau kontribusi peserta bukan sebagai pemilik dana kontribusi. Dana tabarru' tetap menjadi milik peserta dan digunakan untuk membantu peserta lain yang terkena musibah. Mekanisme pengelolaan dana tabarru' (kontribusi) dalam asuransi syariah terbagi menjadi dua sistem, yaitu sistem yang mengandung tabungan dan sistem yang tidak mengandung tabungan (Muhammad, 2007:88). 
Ningsih, et al/Jurnal Ekonomi Syariah Teori dan Terapan Vol. 4 No. 9 September 2017: 757-772; ANALISIS EFISIENSI ASURANSI UMUM SYARIAH DI INDONESIA TAHUN 2013-2015: APLIKASI METODE DATA ENVELOPMENT ANALYSIS (DEA)

\section{Konsep Efisiensi}

Efisiensi secara umum adalah perbandingan antara output dengan input. Suatu perusahaan dapat dikatakan efisien jika mampu mengelola input secara optimal untuk menghasilkan output yang maksimal.

Menurut Farrel (1957) dalam Kristiyanto (2010:20), Efisiensi suatu perusahaan terdiri dari dua komponen, yaitu efisiensi teknik dan efisiensi alokatif. Keduanya dikombinasikan untuk menghasilkan efisiensi total atau efisiensi ekonomis. Efisiensi teknik yaitu hubungan operasional dalam penggunaan input untuk memproduksi output relative pada best practice dalam Decision Making Unit. Efisiensi alokatif adalah kemampuan perusahaan menghasilkan output dengan kombinasi biaya input terendah, dengan catatan secara teknik sudah efisien. Efisiensi ekonomi yaitu jika perusahaan mampu menimimalkan biaya produksi untuk menghasilkan output tertentu dengan suatu tingkat teknologi yang umumnya digunakan dan harga pasar yang berlaku (Mala, 2015:18).

Menurut Yazar A. Oscan (2008) dalam Budi (2010:19), pengukuran efisiensi dapat dilakukan dengan metode, yaitu:

\section{Analisis Rasio}

Adalah metode penilaian efisiensi yang paling sederhana karena hanya menghasilkan informasi dari hubungan satu input dan satu output. Berikut formula dari analisis rasio:
Efisiensi $=\frac{\text { output }}{\text { input }}$

2. Regresi Kuadrat Terkecil

Adalah metode yang mempertimbangkan distribusi data dan mengasumsikan semua entitas efisien. Berikut formula dari regresi linier berganda: $y=\beta_{0}+\beta_{1} x_{1}+\beta_{2} x_{2}+\ldots \ldots+\beta_{n} x_{n}+e$.

\section{Total Faktor Productivity}

Metode TFP diukur menggunakan angka indeks, yang dapat mengukur perubahan harga dan kuantitas sepanjang waktu. Formulasi TFP adalah: TFPab $=\frac{\sum_{i=1}^{N} \text { PibQib }}{\sum_{i=1}^{N} \text { PiaQia }}$

Indeks TFPab mengukur perubahan nilai output sejumlah $\mathrm{N}$ terpilih dari periode "a" ke "b", dimana p yaitu harga output.

\section{Stochastic Frontier Analysis}

Adalah metode parametrik yang mengasumsikan bahwa semua entitas adalah tidak efisien, efisiensi mengikuti distribusi asimetrik, serta data terdistribusi normal. Formulasi SFA adalah:

$\mathrm{TC}=\mathrm{TC}(\mathrm{Y}, \mathrm{W})+\mathrm{V}+\mathrm{U}$.

Keterangan:

$\begin{array}{ll}\text { TC } & \text { : Total biaya Y : Output } \\ \text { W } & \text { : Harga output } \\ \mathrm{V} & \text { : Random error } \\ \mathrm{U} & \text { : Inefficiency residual }\end{array}$

5. Data Envelopment Analysis (DEA) Adalah metode non parametrik, yaitu metode statistika bebas sebaran yang biasanya digunakan untuk melakukan analisis pada data berjenis nominal atau ordinal. Asumsi yang dipakai 
Ningsih, et al/Jurnal Ekonomi Syariah Teori dan Terapan Vol. 4 No. 9 September 2017: 757-772; ANALISIS EFISIENSI ASURANSI UMUM SYARIAH DI INDONESIA TAHUN 2013-2015: APLIKASI METODE DATA ENVELOPMENT ANALYSIS (DEA)

dalam metode ini tidak ada random error dan tidak semua entitas adalah efisien.

\section{Konsep Efisiensi Dalam Ekonomi Islam}

Konsep efisiensi dalam ekonomi Islam berkaitan dengan upaya menjaga salah satu maqashid syariah yaitu al-maal (harta). Konsep terpeliharanya harta dapat dicapai yaitu dengan menjauhi hal-hal yang berkaitan dengan hidup boros. Pemeliharaan harta wajib dilakukan oleh setiap individu maupun kelompok orang dalam organisasi agar tercapai suatu kemaslahatan. Konsep efisien dalam ekonomi Islam, tercermin dalam firman Allah pada surat Al-Israa' ayat 26-27:

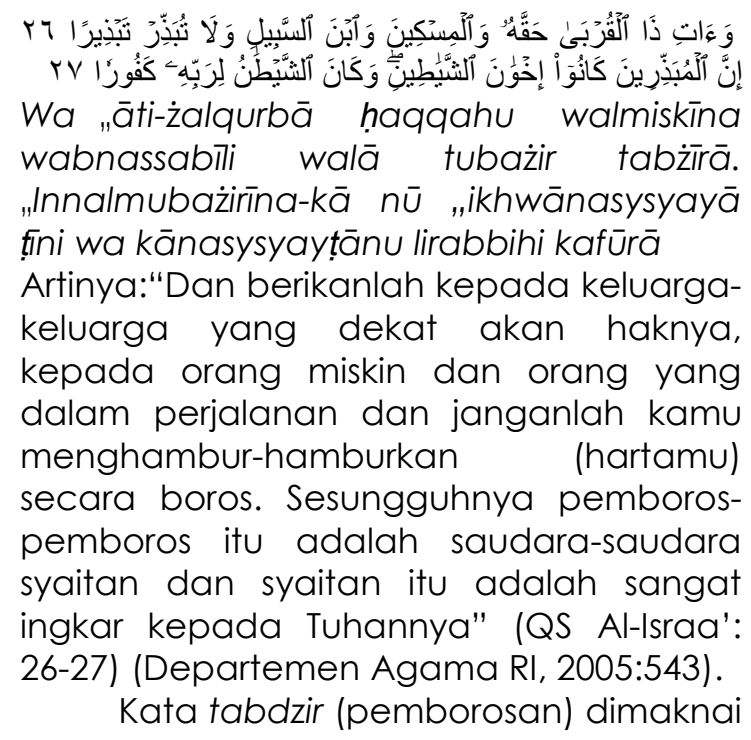
dengan pengeluaran yang bukan haq. Seorang pemboros dikategorikan sebagai saudara setan. (Shihab, 2002:72-73). Hal ini berarti bahwa manusia dalam menggunakan sumber daya yang harus sesuai dengan kebutuhan.

\section{Konsep Efisiensi Perusahaan Asuransi Syariah}

Menurut Eling (2009:14) terdapat dua pendekatan dalam menentukan hubungan input dan output, antara lain:
1. Pendekatan Nilai Tambah. Pendekatan ini adalah gabungan dari pendekatan produksi dan pendekatan intermediasi yang mengasumsikan bahwa perusahaan asuransi menyediakan tiga layanan utama yaitu:

a. Perusahaan asuransi mengoperasikan risk pooling dan risk bearing. Perusahaan asuransi menerima premi dari peserta dan mendistribusikan kembali kepada peserta yang mengalami kerugian.

b. Perusahaan asuransi memberikan layanan 'real' berupa program perlindungan.

c. Perusahaan asuransi sebagai perantara keuangan dengan menginvestasikan dananya dan dana dari peserta pada pasar modal kemudian digunakan untuk memenuhi kewajiban pembayaran klaim peserta.

2. Pendekatan Intermediasi adalah pendekatan yang mengasumsikan perusahaan asuransi sebagai perantara keuangan. Perusahaan asuransi mengelola aset, meminjam dana dari pemegang polis, dan menginvestasikannya serta hasilnya digunakan untuk membayar klaim asuransi, pajak dan biaya lainnya.

Berdasarkan penjelasan diatas, maka pada penelitian ini menggunakan pendekatan nilai tambah dengan total aset, beban, dan pembaran klaim sebagai variabel input dan variabel 
Ningsih, et al/Jurnal Ekonomi Syariah Teori dan Terapan Vol. 4 No. 9 September 2017: 757-772; ANALISIS EFISIENSI ASURANSI UMUM SYARIAH DI INDONESIA TAHUN 2013-2015: APLIKASI METODE DATA ENVELOPMENT ANALYSIS (DEA)

output berupa pendapatan dan dana tabarru' (Benarda, 2015:67). Variabel input dan output tersebut memproxykan ketiga layanan utama perusahaan asuransi.

\section{Konsep Data Envelopment Analysis (DEA)}

DEA adalah sebuah teknik aplikasi program linier yang mengukur efisiensi relatif dari setiap unit produksi dibandingkan dengan unit produksi lainnya yang memiliki tujuan yang sama. Efisiensi relatif suatu DMU adalah efisiensi suatu DMU dibandingkan dengan DMU lain dalam sampel yang menggunakan jenis input dan output yang sama. Unit produksi dalam DEA disebut sebagai Decision-Making Unit (DMU). Skor efisiensi yang dihasilkan DEA berkisar antara 0-100 persen. DMU yang memiliki skor kurang dari 100 persen dianggap sebagai unit yang relatif tidak efisien.

Beberapa hal penting yang harus diperhatikan dalam pemilihan DMU yaitu (Indrawati, 2009:27):

1. Positivity, yaitu semua variabel input dan output harus bernilai positif

2. Isotonicity, berarti setiap kenaikan variabel input harus menaikkan setidaknya satu variabel output dan tidak ada variabel output yang turun.

3. Jumlah DMU, setidaknya jumlah DMU sebesar 3 kali dari jumlah variabel input dan output.

4. Window Analysis, diperlukan jika terjadi pemecahan data DMU.

5. Penentuan bobot

6. Homogeneity, variabel seluruh DMU sama jenisnya.

Langkah kerja metode DEA meliputi:
1. Identifikasi DMU atau unit yang akan diobservasi berserta input dan output pembentuknya.

2. Menghitung efisiensi tiap DMU untuk mendapatkan target input dan output yang diperlukan untuk mencapai kinerja optimal.

Pada pengukuran efisiensi, ada dua orientasi yang digunakan, yaitu (Indrawati, 2009:29-30)

1. Orientasi input

Prespektif yang melihat efisiensi sebagai pengurangan penggunaan input meski memproduksi output dalam jumlah yang tetap.

2. Orientasi output

Prespektif yang melihat efisiensi sebagai peningkatan output secara proporsional dengan menggunakan input yang sama.

\section{Model DEA}

1. Model Constant Return to Scale (CRS) Model CRS ini dikembangkan oleh Charnes, Cooper, dan Rhodes tahun 1978. Awalnya model ini dikenal dengan model CCR. Asumsinya adalah rasio antara penambahan input dan output sama, yang berarti bahwa jika ada tambahan input sebesar $x$ kali, maka output akan meningkat sebesar $x$ kali juga. Model ini mengasumsikan bahwa setiap DMU beroperasi pada skala yang optimal. Rumus CRS menurut Moussawi dan Obeid (2011) dalam Sari (2015:41-42) adalah:

$$
\operatorname{Maxh}_{k}=\frac{\sum_{\gamma=1}^{S} u_{i} y_{T j}}{\sum_{i=1}^{m} u_{i} x_{i j}} \text {. }
$$

Dimana:

$h_{k}=$ Nilai efisiensi operasional 
$\sum_{r=1}^{s} u_{r} y_{r j}=$ Output terbobot

$\sum_{i=1}^{m} u_{i} x_{i j}=$ Input terbobot

Dengan fungsi kendala:

$$
\begin{aligned}
& \frac{\sum_{r=1}^{s} u_{r} y_{r j}}{\sum_{i=1}^{m m} u_{i} x_{i j}} \leq 1 \\
& U_{i} \geq 0, \quad y_{i} \geq 0
\end{aligned}
$$

Pengukuran efisiensi dengan model CRS merupakan pengukuran overall technical efficiency (OTE) atau pengukuran efisiensi kotor (gross efficiency) yang merupakan gabungan dari efisiensi teknis dan skala.

2. Model VRS (Variabel Return to Scale) Model VRS dikembangkan oleh Banker, Charnes, dan Coopper (model BCC) pada tahun 1984 yang merupakan model pengembangan CCR. Model ini beranggapan bahwa perusahaan belum atau tidak beroperasi dalam skala optimal sehingga rasio antara penambahan input dan output tidak sama, yang berarti penambahan input sebesar $x$ kali tidak akan menyebabkan output meningkat sebesar $x$ kali, bisa lebih kecil atau lebih besar dari $x$ kali. Rumus BCC menurut Moussawi dan Obeid (2011) dalam Sari (2015:42) adalah:

$\min h_{k}$

$\sum_{j=1}^{n} u_{j} y_{r j} \geq y_{r k}$

$\sum_{j=1}^{n} u_{j} x_{i j} \leq h_{k} x_{i k}$

$\sum_{i=1}^{n} \mathrm{U}_{j}=1$

$u_{j} \geq 0$

Pengukuran efisiensi dengan VRS akan membedakan nilai efisiensi menjadi dua, yaitu pure Technical Efficiency (PTE) dan efisiensi skala (Scale Efficiency).
Perhitungan efisiensi dengan DEA lebih lanjut akan menjelaskan unit yang efisien dan unit yang tidak efisien melalui hasil peer group dan penetapan target. Peer group digunakan untuk menentukan DMU acuan bagi DMU yang inefisiensi untuk meningkatkan efisiensinya. Penetapan target ditentukan melalui slack variabel, sedangkan koefisien dari slack variabel diperoleh dari kinerja peer group untuk masing-masing DMU. Target perbaikan dapat berupa meminimisasi input atau memaksimisasi output.

\section{Kerangka Berpikir}

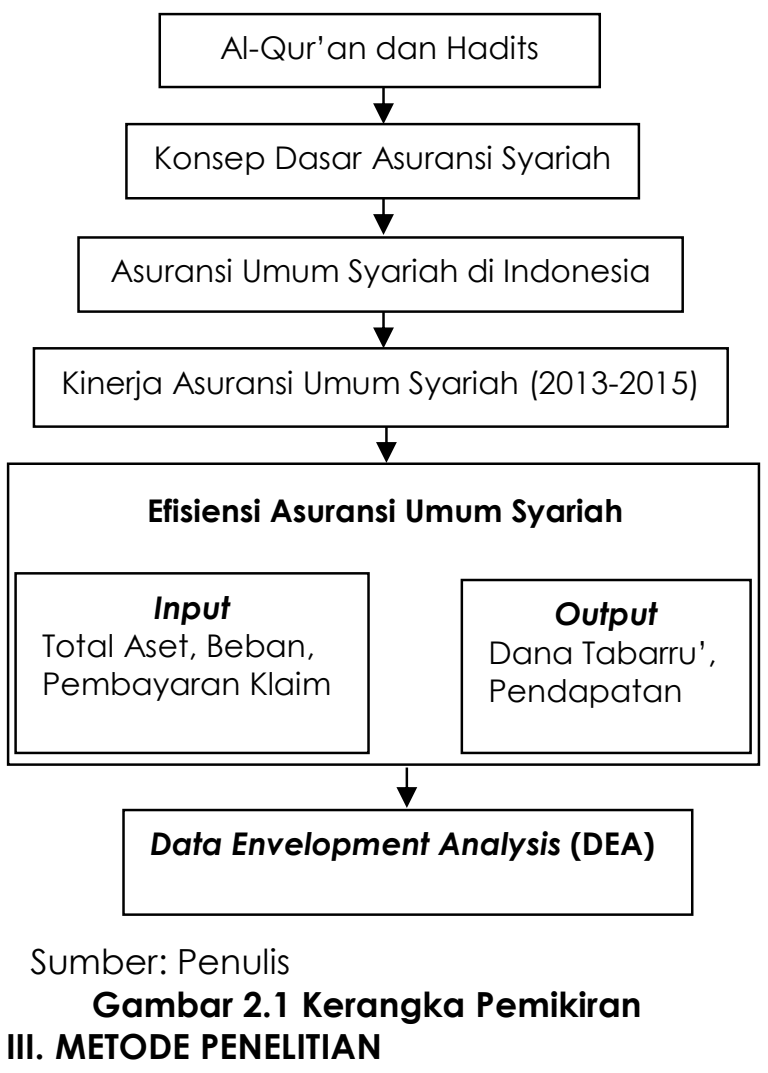

Pendekatan Penelitian

Pendekatan penelitian yang digunakan adalah pendekatan kuantitatif dengan menggunakan metode Data Envelopment Analysis (DEA). Pendekatan untuk menentukan variabel input dan output adalah pendekatan nilai tambah. 
Ningsih, et al/Jurnal Ekonomi Syariah Teori dan Terapan Vol. 4 No. 9 September 2017: 757-772; ANALISIS EFISIENSI ASURANSI UMUM SYARIAH DI INDONESIA TAHUN 2013-2015: APLIKASI METODE DATA ENVELOPMENT ANALYSIS (DEA)

Pendekatan ini dipakai untuk mengevaluasi perusahaan asuransi umum syariah secara keseluruhan baik dalam mengelola dana perusahaan maupun dana tabarru'.

\section{Identifikasi Variabel}

Adapun penentuan variabel input dan output dalam penelitian ini mengacu pada jurnal Benarda, dkk. (2015: 67), yaitu: Variabel input: Total Aset, Beban, dan Pembayaran Klaim

Variabel output: Pendapatan dan dana tabarru'.

\section{Definisi Operasional Variabel}

1. Total aset (I1) yaitu sesuatu yang dimiliki oleh perusahaan dalam mengembangkan, menciptakan produk, dan aktivitas lainnya. Total aset ini terdiri dari kas dan setara kas, piutang kontribusi, piutang reasuransi, piutang, investasi pada surat berharga, pembiayaan, investasi pada entitas lain, properti investasi, aset tetap, dan aset lainnya. Nilai Total Aset ini dapat dilihat dalam Laporan Neraca Perusahaan.

2. Beban (I2) yaitu sesuatu yang dikeluarkan oleh perusahaan untuk menghasilkan pendapatan periode berjalan. Beban ini terdiri atas beban komisi, ujroh dibayar, beban umum dan administrasi, beban pemasaran, serta beban pengembangan. Nilai Beban ini dapat dilihat di Laporan Laba Rugi Dana Perusahaan.

3. Pembayaran klaim (13) yaitu pembayaran pengajuan kerugian peserta terhadap perusahaan asuransi umum syariah. Pembayaran klaim ini bagian dari beban asuransi dalam Laporan Surplus (Defisit) Underwriting Dana Tabarru'.

4. Pendapatan (O1) yaitu penghasilan perusahaan asuransi umum syariah atas aktivitas yang dilakukan. Pendapatan ini terdiri dari pendapatan pengelolaan operasi asuransi, pendapatan pengelolaan portofolio investasi dana peserta, pendapatan pembagian surplus underwriting, dan pendapatan investasi. Nilai pendapatan dapat dilihat di Laporan Laba Rugi Dana Perusahaan.

5. Dana tabarru' (O2) yaitu kontribusi peserta berasal dari komponen kontribusi berbagi risiko yang telah dihibahkan oleh masing-masing peserta sebagai perwujudan niat membantu sesama peserta yang lain jika suatu hari tertimpa musibah. Dana tabarru' ini merupakan kepemilikan kolektif bagi peserta asuransi syariah dan merupakan bagian dari dana peserta dalam laporan keuangan (neraca) perusahaan.

\section{Jenis dan Sumber Data}

Pada penelitian ini data sekunder. Semua data berasal dari data laporan keuangan perusahaan asuransi umum syariah tahun 2013-2015 yang diambil dari website masing-masing perusahaan pasca audit. Pengumpulan data dilakukan melalui metode kepustakaan.

\section{Populasi dan Sampel}


Ningsih, et al/Jurnal Ekonomi Syariah Teori dan Terapan Vol. 4 No. 9 September 2017: 757-772; ANALISIS EFISIENSI ASURANSI UMUM SYARIAH DI INDONESIA TAHUN 2013-2015: APLIKASI METODE DATA ENVELOPMENT ANALYSIS (DEA)

Populasi dalam penelitian ini adalah seluruh asuransi umum syariah baik berbentuk UUS maupun full fledge yang terdaftar di Otoritas Jasa Kevangan (OJK) sebanyak 28 perusahaan. Sampel ditentukan dengan metode purposive sampling, yaitu pengambilan sampel yang memenuhi kriteria tertentu yang dikendaki. Kriteria sampel yang dikehendaki adalah perusahaan asuransi umum syariah yang memiliki data lengkap bernilai positif yang berkaitan dengan variabel yang digunakan selama tahun 2013 hingga 2015.

Berdasarkan kriteria diatas sampel yang digunakan dalam pada penelitian ini sebanyak 12 perusahaan, yang terdiri dari PT Asuransi Adira Dinamika (UUS), PT Asuransi Allianz Utama Indonesia (UUS), PT Asuransi Astra Buana (UUS), PT Asuransi Bangun Askrida (UUS), PT Asuransi Bringin Sejahtera Artamakmur (UUS), PT Asuransi Central Asia (UUS), PT Asuransi Jasa Raharja Putera (UUS), PT Asuransi Sinar Mas (UUS), PT Asuransi Staco Mandiri (UUS), PT Asuransi Umum Mega (UUS), PT Tugu Pratama Indonesia (UUS), dan PT Asuransi Takaful Umum(Full Fledge).

\section{Teknik Analisis}

Penelitian ini menggunakan teknik analisis DEA dengan asumsi VRS untuk mengukur nilai efisiensi perusahaan asuransi umum syariah. Hasil pengukuran efisiensi akan menghasilkan nilai efisiensi teknis dan efisiensi skala yang dirumuskan:

$\mathrm{SE}=\frac{O E}{T E}$

Dimana:
SE: Scale Efficiency

OE: Overall Efficiency (Model CRS)

TE: Technical Efficiency (Model VRS)

Pengukuran efisiensi pada penelitian ini menggunakan bantuan perangkat aplikasi Data Envelopment Analysis Programme (DEAP) 2.1 Version. DMU yang memiliki nilai efisiensi 1 (satu) merupakan DMU yang efisien, sedangkan DMU dengan nilai efisiensi kurang dari 1 (satu) adalah DMU yang inefisien. Selanjutnya, dari nilai efisiensi yang dihasilkan akan diidentifikasi unsur yang menyebabkan inefisien serta menjadikan DMU yang relatif efisien sebagai acuan bagi DMU yang inefisien.

Pengukuran efisiensi dengan asumsi model VRS karena tidak semua DMU beroperasi pada skala yang optimal. Ada faktor persaingan tidak sempurna, teknologi dan kondisi keuangan yang berbeda, sehingga kondisi optimal tersebut sulit dicapai khususnya oleh lembaga keuangan (Budi, 2010:27). Orientasi yang digunakan adalah orientasi input dan output. Orientasi input digunakan sebab manajemen memiliki kontrol lebih terhadap input daripada output. Sedangkan orientasi output digunakan karena diasumsikan industri asuransi umum syariah di Indonesia sangat kompetitif, hal ini ditunjukkan dengan semakin banyaknya jumlah asuransi umum syariah di Indonesia.

\section{HASIL DAN PEMBAHASAN}

Berdasarkan hasil penelitian dengan asumsi VRS, maka dapat disimpulkan bahwa kinerja asuransi umum syariah di 
Indonesia selama tahun 2013-2015 belum efisien, baik secara ekonomi, teknik, maupun skala. Nilai rata-rata efisiensi teknik sebesar 0.978, secara ekonomi sebesar 0.924, serta efisiensi skala sebesar 0.945 (Tabel 4.1). Hal ini menunjukkan bahwa sebagian asuransi umum syariah yang diteliti belum cukup dapat menghimpun pendapatan dan dana tabarru'. Sumber ketidakefisienan perusahaan asuransi umum syariah ini disebabkan oleh pengelolaan input dan output, serta skala usaha yang belum optimal.

Tabel 4.1

Sebaran Efisiensi Asuransi Umum Syariah Dalam Satuan Unit

\begin{tabular}{lccc}
\hline Skor Efisiensi & $\begin{array}{c}\text { CRS } \\
\text { (Ekonomi) }\end{array}$ & $\begin{array}{c}\text { VRS } \\
\text { (Teknis) }\end{array}$ & Scale \\
\hline 1 & 19 & 30 & 19 \\
$0,0001-0,9999$ & 17 & 6 & 17 \\
Total & 36 & 36 & 36 \\
Rata-rata & 0,924667 & 0,978 & 0,945 \\
\hline
\end{tabular}

Sumber: Data Hasil Penelitian (diolah)

Secara umum, tren rata-rata nilai efisiensi baik secara CRS, VRS, maupun Skala mengalami penurunan pada tahun 2014 (Gambar 4.1). Hal ini disebabkan oleh penuruan pertumbuhan, dan pembiayaan perbankan syariah, serta perlambatan pertumbuhan ekonomi Indonesia juga berdampak pada sikap nasabah yang lebih selektif sebelum mengikuti program perlindungan asuransi syariah. Pada Tahun 2014 terjadi kenaikan klaim sebesar 18,81\%, namun tidak sebanding dengan pertumbuhan kontribusi yang hanya sebesar $4,53 \%$. Hal ini merupakan indikasi asuransi syariah untuk melakukan kajian kembali dalam proses pengelolaan risiko asuransi syariah
(Data Bisnis Asuransi dan Reasuransi Syariah TW IV, 2014:12).

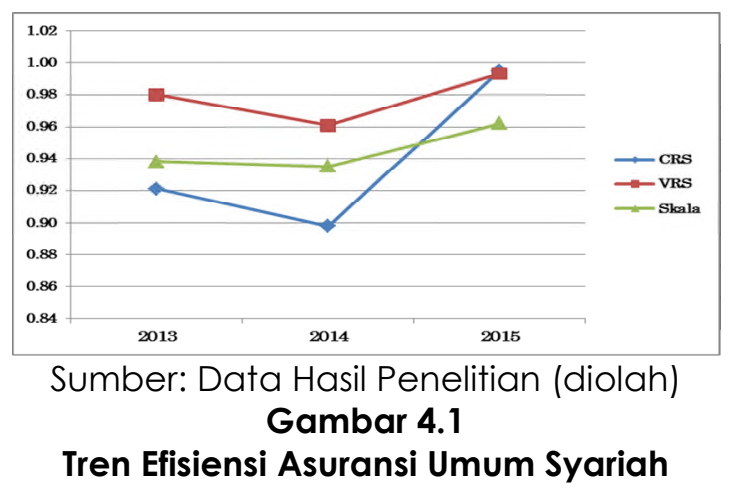

Berikut ini adalah daftar perusahaan yang efisien selama tahun 2013-2015:

Tabel 4.2

Daftar Perusahaan yang Efisien

\begin{tabular}{|c|c|}
\hline $\begin{array}{c}\text { CRS (Ekonomi) } \\
\text { dan Scale } \\
\text { Efficiency }\end{array}$ & VRS (Teknik) \\
\hline $\begin{array}{l}\text { PT Asuransi Bangun } \\
\text { Askrida (UUS) } \\
\text { PT Asuransi Jasa } \\
\text { Raharja Putera } \\
\text { (UUS) } \\
\text { PT Asuransi Sinar } \\
\text { Mas (UUS) }\end{array}$ & 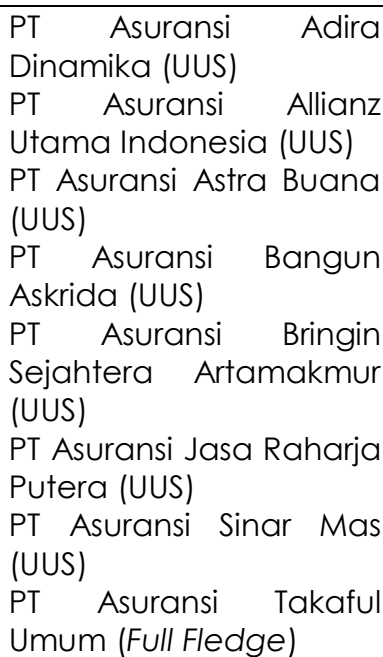 \\
\hline
\end{tabular}

Sumber: Data Hasil Penelitian (diolah)

Komposisi (jumlah DMU) yang efisien secara ekonomi pada masing-masing perusahaan selama periode penelitian adalah 1 (5.26\%) Allianz, 3 (15.79\%) Askrida, 2 (10.53\%) Bringin, 1 (5.26\%) Cental Asia, 3 (15.79\%) Jasa Raharja, 3 (15.79\%) Sinar Mas, 2 (5.26\%) Staco Mandiri, 1 (5.26\%) Umum Mega, 1 (5.26\%) Tugu, dan 2 (10.53\%) Takaful Umum. Tidak ada DMU yang efisien untuk Asuransi Adira dan Astra Buana. 
Komposisi DMU yang efisien secara teknik pada masing-masing perusahaan adalah 3 (10.00\%) Adira, 3 (10.00\%) Allianz, 3 (10.00\%) Astra Buana, 3 (10.00\%) Askrida, 3 (10.00\%) Bringin, 2 (6.67\%) Central Asia, 3 (10.00\%) Jasa Raharja, 3 (10.00\%) Sinar Mas, 2 (6.67\%) Staco Mandiri, 1 (3.33\%) Umum Mega, 1 (3.33\%) Tugu, dan 3 (10.00\%) Takaful Umum.

\section{Penentuan Peer-Group dan Penetapan Target}

Berdasarkan Tabel 4.3, perusahaan Asuransi Tugu mempunyai nilai efisiensi 0,833, untuk meningkatkan efisiensinya, dengan orientasi input pada tahun 2013 maka DMU yang bisa dijadikan acuan adalah asuransi bringin, sinar mas, dan askrida. Adapun contoh perhitungannya: Input Tugu $2013=(0,117 \times$ input Sinar Mas $)$ $+(0,718 x$ input Bringin 2013) $+(0,165 x$ input Askrida)

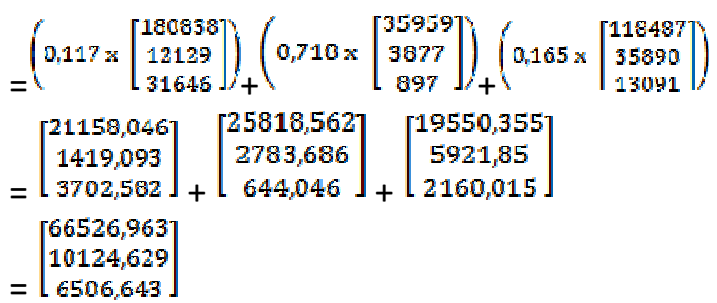

Berdasarkan contoh perhitungan tersebut, maka dapat disimpulkan bahwa untuk meningkatkan efisiensinya dengan orientasi input perusahaan Asuransi Tugu harus mampu menurunkan input total aset yang sebelumnya Rp 79.800.000.000,menjadi Rp 66.526.963.000,-, input beban yang sebelumnya Rp 12.144.000.000,menjadi Rp 10.124.629.000,- dan input pembayaran klaim yang sebelumnya Rp 26.843.000.000,- menjadi Rp 6504.149.000,-. Penurunan nilai input total aset berarti bahwa perusahaan Asuransi Tugu harus memperbaiki pengelolaan asetnya agar lebih produktif. Nilai input yang harus dicapai merupakan target yang ditetapkan untuk perusahaan Asuransi Tugu untuk mencapai efisiensi teknik.

Tabel 4.3

Peer-Group Asuransi Umum Syariah Tahun 2013-2015

\begin{tabular}{|c|c|c|c|c|c|c|c|}
\hline \multicolumn{8}{|c|}{ ORIENTASI INPUT } \\
\hline $\begin{array}{l}\text { Th } \\
\text { n }\end{array}$ & DMU & VRS & & 1 & 2 & 3 & 4 \\
\hline \multirow[t]{2}{*}{$\begin{array}{l}20 \\
13\end{array}$} & Mega & $\begin{array}{c}0,92 \\
7\end{array}$ & $\begin{array}{c}\text { DMU } \\
\text { Acua } \\
n\end{array}$ & $\begin{array}{c}\text { Sina } \\
r \\
\text { Mas } \\
\end{array}$ & $\begin{array}{l}\text { Bring } \\
\text { in }\end{array}$ & $\begin{array}{c}\text { Askri } \\
\text { da }\end{array}$ & \\
\hline & & & $\begin{array}{l}\text { Multip } \\
\text { lier }\end{array}$ & $\begin{array}{c}0,31 \\
1 \\
\end{array}$ & 0,381 & 0,308 & \\
\hline \multirow[t]{2}{*}{$\begin{array}{l}20 \\
13\end{array}$} & Tugu & $\begin{array}{c}0,83 \\
3\end{array}$ & $\begin{array}{c}\text { DMU } \\
\text { Acua } \\
n\end{array}$ & $\begin{array}{c}\text { Sina } \\
r \\
\text { Mas }\end{array}$ & $\begin{array}{c}\text { Bring } \\
\text { in }\end{array}$ & $\begin{array}{c}\text { Askri } \\
\text { da }\end{array}$ & \\
\hline & & & $\begin{array}{c}\text { Multip } \\
\text { lier }\end{array}$ & $\begin{array}{c}0,11 \\
7 \\
\end{array}$ & 0,718 & 0,165 & \\
\hline \multirow[t]{2}{*}{$\begin{array}{l}20 \\
14\end{array}$} & $\begin{array}{c}\text { Centr } \\
\text { al } \\
\text { Asia }\end{array}$ & $\begin{array}{c}0,70 \\
1\end{array}$ & $\begin{array}{c}\text { DMU } \\
\text { Acua } \\
n\end{array}$ & $\begin{array}{l}\text { Brin } \\
\text { gin }\end{array}$ & $\begin{array}{c}\text { Askri } \\
\text { da }\end{array}$ & $\begin{array}{c}\text { Taka } \\
\text { ful } \\
\text { Umu } \\
m\end{array}$ & \\
\hline & & & $\begin{array}{l}\text { Multip } \\
\text { lier }\end{array}$ & $\begin{array}{c}0,22 \\
8 \\
\end{array}$ & 0,766 & 0,006 & \\
\hline \multirow[t]{2}{*}{$\begin{array}{l}20 \\
14\end{array}$} & $\begin{array}{l}\text { Staco } \\
\text { Mand } \\
\text { iri }\end{array}$ & $\begin{array}{c}0,93 \\
4\end{array}$ & $\begin{array}{c}\text { DMU } \\
\text { Acua } \\
n\end{array}$ & $\begin{array}{l}\text { Askr } \\
\text { ida }\end{array}$ & $\begin{array}{c}\text { Meg } \\
\text { a }\end{array}$ & $\begin{array}{l}\text { Jasa } \\
\text { Rah } \\
\text { arja }\end{array}$ & Bringin \\
\hline & & & $\begin{array}{c}\text { Multip } \\
\text { lier }\end{array}$ & $\begin{array}{c}0,18 \\
0 \\
\end{array}$ & 0,075 & 0,698 & 0,046 \\
\hline \multirow[t]{2}{*}{$\begin{array}{l}20 \\
14\end{array}$} & Tugu & $\begin{array}{c}0,86 \\
0\end{array}$ & $\begin{array}{c}\text { DMU } \\
\text { Acua } \\
n\end{array}$ & $\begin{array}{c}\text { Sina } \\
r \\
\text { Mas }\end{array}$ & $\begin{array}{c}\text { Meg } \\
\text { a }\end{array}$ & $\begin{array}{c}\text { Askri } \\
\text { da }\end{array}$ & Allianz \\
\hline & & & $\begin{array}{c}\text { Multip } \\
\text { lier }\end{array}$ & $\begin{array}{c}0,08 \\
0 \\
\end{array}$ & 0,160 & 0,005 & 0,755 \\
\hline \multirow[t]{2}{*}{$\begin{array}{l}20 \\
15\end{array}$} & Mega & $\begin{array}{c}0,91 \\
8\end{array}$ & $\begin{array}{c}\text { DMU } \\
\text { Acua } \\
n\end{array}$ & $\begin{array}{l}\text { Askr } \\
\text { ida }\end{array}$ & $\begin{array}{l}\text { Sinar } \\
\text { Mas }\end{array}$ & $\begin{array}{c}\text { Bring } \\
\text { in }\end{array}$ & Tugu \\
\hline & & & $\begin{array}{c}\text { Multip } \\
\text { lier }\end{array}$ & $\begin{array}{c}0,22 \\
3 \\
\end{array}$ & 0,239 & 0,438 & 0,100 \\
\hline \multicolumn{8}{|c|}{ ORIENTASI OUTPUT } \\
\hline $\begin{array}{l}\text { Th } \\
\mathrm{n}\end{array}$ & DMU & VRS & & 1 & 2 & 3 & 4 \\
\hline \multirow[t]{2}{*}{$\begin{array}{l}20 \\
13\end{array}$} & Mega & $\begin{array}{c}0,91 \\
5\end{array}$ & $\begin{array}{c}\text { DMU } \\
\text { Acua } \\
n\end{array}$ & $\begin{array}{c}\text { Sina } \\
r \\
\text { Mas } \\
\end{array}$ & $\begin{array}{c}\text { Bringi } \\
n\end{array}$ & $\begin{array}{c}\text { Askri } \\
\text { da }\end{array}$ & \\
\hline & & & $\begin{array}{l}\text { Multip } \\
\text { lier }\end{array}$ & $\begin{array}{c}0,35 \\
2 \\
\end{array}$ & 0,310 & 0,338 & \\
\hline \multirow[t]{2}{*}{$\begin{array}{l}20 \\
13\end{array}$} & Tugu & $\begin{array}{c}0,79 \\
2\end{array}$ & $\begin{array}{c}\text { DMU } \\
\text { Acua } \\
n\end{array}$ & $\begin{array}{c}\text { Sina } \\
r \\
\text { Mas } \\
\end{array}$ & $\begin{array}{c}\text { Bringi } \\
n\end{array}$ & $\begin{array}{c}\text { Askri } \\
\text { da }\end{array}$ & \\
\hline & & & $\begin{array}{c}\text { Multip } \\
\text { lier }\end{array}$ & $\begin{array}{c}0,18 \\
2 \\
\end{array}$ & 0,606 & 0,211 & \\
\hline \multirow[t]{2}{*}{$\begin{array}{l}20 \\
14\end{array}$} & $\begin{array}{c}\text { Centr } \\
\text { al } \\
\text { Asia }\end{array}$ & $\begin{array}{c}0,83 \\
0\end{array}$ & $\begin{array}{c}\text { DMU } \\
\text { Acua } \\
n\end{array}$ & $\begin{array}{l}\text { Askr } \\
\text { ida }\end{array}$ & $\begin{array}{c}\text { Taka } \\
\text { ful } \\
\text { Umu } \\
m\end{array}$ & & \\
\hline & & & $\begin{array}{c}\text { Multip } \\
\text { lier }\end{array}$ & $\begin{array}{c}0,94 \\
2 \\
\end{array}$ & 0,058 & & \\
\hline \multirow[t]{2}{*}{$\begin{array}{l}20 \\
14\end{array}$} & $\begin{array}{c}\text { Staco } \\
\text { Mand } \\
\text { iri }\end{array}$ & $\begin{array}{c}0,94 \\
2\end{array}$ & $\begin{array}{c}\text { DMU } \\
\text { Acua } \\
n\end{array}$ & $\begin{array}{l}\text { Askr } \\
\text { ida }\end{array}$ & $\begin{array}{c}\text { Meg } \\
\text { a }\end{array}$ & $\begin{array}{l}\text { Jasa } \\
\text { Rah } \\
\text { arja }\end{array}$ & Bringin \\
\hline & & & $\begin{array}{l}\text { Multip } \\
\text { lier }\end{array}$ & $\begin{array}{c}0,20 \\
0\end{array}$ & 0,077 & 0,664 & 0,059 \\
\hline
\end{tabular}




\begin{tabular}{|c|c|c|c|c|c|c|c|}
\hline $\begin{array}{l}20 \\
14\end{array}$ & Tugu & $\begin{array}{c}0,85 \\
1\end{array}$ & $\begin{array}{c}\text { DMU } \\
\text { Acua } \\
n\end{array}$ & $\begin{array}{c}\text { Sina } \\
r \\
\text { Mas }\end{array}$ & $\begin{array}{c}\text { Meg } \\
\text { a }\end{array}$ & $\begin{array}{c}\text { Allia } \\
n z\end{array}$ & $\begin{array}{c}\text { Askrid } \\
\text { a }\end{array}$ \\
\hline & & & $\begin{array}{c}\text { Multip } \\
\text { lier }\end{array}$ & $\begin{array}{c}0,10 \\
3 \\
\end{array}$ & 0,170 & 0,675 & 0,052 \\
\hline $\begin{array}{l}20 \\
15\end{array}$ & Mega & $\begin{array}{c}0,92 \\
7\end{array}$ & $\begin{array}{c}\text { DMU } \\
\text { Acua } \\
n\end{array}$ & $\begin{array}{l}\text { Brin } \\
\text { gin }\end{array}$ & $\begin{array}{c}\text { Askri } \\
\text { da }\end{array}$ & $\begin{array}{l}\text { Sinar } \\
\text { Mas }\end{array}$ & $\begin{array}{l}\text { Centr } \\
\text { al Asia }\end{array}$ \\
\hline & & & $\begin{array}{c}\text { Multip } \\
\text { lier }\end{array}$ & $\begin{array}{c}0,48 \\
8\end{array}$ & 0,242 & 0,266 & 0,004 \\
\hline
\end{tabular}

Sumber: Data Hasil Penelitian (diolah)

Berdasarkan hasil penelitian di Tabel 4.3 memperlihatkan bahwa Asuransi Tugu Pratama inefisien pada tahun 2013 dan 2014 dan rata-rata nilai efisiennya relatif kecil, sehingga perbaikan dapat dilakukan pada perusahaan ini. Ketidakefisienan Asuransi Tugu bersumber dari alokasi output pendapatan dan dana tabarru' yang masih bisa ditingkatkan dengan mengelola input yang sama secara lebih optimal lagi. Penambahan input justru akan menurunkan efisiensi sebab input yang ada masih belum optimal penggunaannya. Kondisi ini disebut Increasing Return to Scale (IRS).

Pada tahun 2014, rata-rata improvement input oriented VRS, Asuransi Tugu Pratama menunjukkan bahwa Asuransi Tugu Pratama harus menurunkan aset sebesar 12,07\%, beban sebesar $12,27 \%$, dan pembayaran klaim sebesar $12,28 \%$. Penurunan klaim sebesar $12,28 \%$ ini bermakna bahwa Asuransi Tugu Pratama harus memperbaiki proses underwriting sehingga penurunan klaim sebesar 12,28\% dapat dihindari. Perbaikan proses underwriting lebih lanjut akan menaikkan saldo dana tabarru'.

\section{Tabel 4.4}

Nilai Aktual dan Target Asumsi VRS Tahun 2014

Dalam Jutaan Rupiah

\begin{tabular}{|l|l|l|l|l|}
\multirow{2}{*}{ Variabel } & \multicolumn{3}{|l|}{ ASURANSI TUGU PRATAMA 2014 (irs) } \\
\cline { 2 - 4 } & Rata-Rata & Per & Rata-Rata & Per \\
\hline
\end{tabular}

\begin{tabular}{|c|c|c|c|c|c|c|}
\hline & \multicolumn{2}{|c|}{$\begin{array}{c}\text { (Orientasi } \\
\text { Input) }\end{array}$} & \multirow[t]{2}{*}{$\begin{array}{l}\text { sen } \\
\text { (\%) }\end{array}$} & \multicolumn{2}{|c|}{$\begin{array}{c}\text { Orientasi } \\
\text { Output) }\end{array}$} & \multirow[t]{2}{*}{$\begin{array}{l}\text { sen } \\
(\%)\end{array}$} \\
\hline & $\begin{array}{l}\text { Akt } \\
\text { ual }\end{array}$ & $\begin{array}{c}\text { Targe } \\
t\end{array}$ & & $\begin{array}{l}\text { Akt } \\
\text { ual }\end{array}$ & $\begin{array}{l}\text { Tar } \\
\text { get }\end{array}$ & \\
\hline Total & 792 & 6967 & 12,0 & 794 & 794 & \\
\hline Aset & 47 & 9,391 & 7 & 27 & 27 & 0,00 \\
\hline \multirow{2}{*}{ Beban } & 547 & 4800 & 12,2 & 547 & 547 & \multirow{2}{*}{0,00} \\
\hline & 2 & 454 & 7 & 2 & 2 & \\
\hline \multirow{2}{*}{$\begin{array}{c}\text { Pembay } \\
\text { aran } \\
\text { Klaim }\end{array}$} & 101 & 8852, & 12,8 & 101 & 101 & \multirow{2}{*}{0,00} \\
\hline & 62 & 220 & 8 & 62 & 62 & \\
\hline \multirow{2}{*}{$\begin{array}{c}\text { Pendap } \\
\text { atan }\end{array}$} & 134 & 1340 & \multirow{2}{*}{0,00} & 134 & 157 & \multirow{2}{*}{$\begin{array}{c}17,5 \\
6\end{array}$} \\
\hline & 09 & 9 & & 09 & $\begin{array}{c}64,3 \\
75\end{array}$ & \\
\hline \multirow{2}{*}{$\begin{array}{c}\text { Dana } \\
\text { Tabarru' }\end{array}$} & 380 & \multirow{2}{*}{3801} & \multirow[b]{2}{*}{0,00} & 380 & 481 & \multirow{2}{*}{$\begin{array}{c}26,6 \\
8\end{array}$} \\
\hline & 1 & & & 1 & $\begin{array}{c}5,31 \\
7\end{array}$ & \\
\hline
\end{tabular}

Sumber: Data Hasil Penelitian (diolah)

$$
\text { Pada tahun 2014, rata-rata }
$$
improvement output oriented VRS Asuransi Tugu Pratama menunjukkan bahwa untuk mencapai efisien maka harus menaikkan output pendapatan sebesar $17,56 \%$ dan dana tabarru' sebesar 26,68\%. Peningkatan saldo dana tabarru' dapat dilakukan dengan menambah jumlah peserta asuransi syariah dengan menawarkan harga yang lebih kompetitif, menjalin kerjasama dengan perusahaan properti yang mensyaratkan adanya program perlindungan dari asuransi umum terhadap barang yang diperjualbelikan, serta melakukan inovasi produk baik untuk korporasi maupun retail. Peningkatan pendapatan dan dana tabarru' ini juga berarti bahwa perusahaan harus lebih cermat lagi dalam melakukan proses underwriting sehingga beban klaim tidak membengkak serta harus lebih optimal lagi dalam hal pengelolaan aset (investasi) agar mampu menghasilkan pendapatan yang lebih besar (Tabel 4.4).

Secara Umum, hasil pengolahan data dengan metode DEA juga 
Ningsih, et al/Jurnal Ekonomi Syariah Teori dan Terapan Vol. 4 No. 9 September 2017: 757-772; ANALISIS EFISIENSI ASURANSI UMUM SYARIAH DI INDONESIA TAHUN 2013-2015: APLIKASI METODE DATA ENVELOPMENT ANALYSIS (DEA)

menyatakan bahwa terdapat $10 \mathrm{DMU}$ berada dalam kondisi DRS (Decreasing Return to Scale) dan tujuh DMU mengalami kondisi IRS (Increasing Return to Scale). Kondisi DRS menuntut adanya pengurangan input, karena jumlah input dengan output yang dihasilkan sudah tidak ideal. Adapun kondisi IRS memungkinkan untuk terus meningkatkan kapasitas hasil output dengan mempertahankan input yang ada, sebab penambahan input justru tidak efektif mengingat sumber daya yang digunakan masih belum berfungsi secara optimal. Berikut ini adalah data DMU yang mengalami kondisi IRS dan DRS:

Tabel 4.5 DMU Kondisi IRS dan DRS

\begin{tabular}{|c|c|c|}
\hline Tahun & IRS & DRS \\
\hline 2013 & $\begin{array}{c}\text { Allianz, Umum } \\
\text { Mega, Tugu }\end{array}$ & $\begin{array}{c}\text { Adira, Astra buana, } \\
\text { Takaful Umum }\end{array}$ \\
\hline 2014 & $\begin{array}{c}\text { Allianz, } \\
\text { Bringin, Staco } \\
\text { Mandiri, Tugu }\end{array}$ & $\begin{array}{c}\text { Adira, Astra buana, } \\
\text { Central Asia }\end{array}$ \\
\hline 2015 & & $\begin{array}{c}\text { Adira, Astra Buana, } \\
\text { Central Asia, Umum } \\
\text { Mega }\end{array}$ \\
\hline
\end{tabular}

Sumber: Data Hasil Penelitian (diolah)

\section{SIMPULAN DAN SARAN}

\section{Simpulan}

Pengukuran efisiensi dengan metode DEA asumsi VRS (Variable Return to Scale) orientasi input dan output menghasilkan tiga skor efisiensi yaitu efisiensi ekonomi (CRS), efisiensi teknik (VRS), dan Efisiensi skala. Hasil ketiga efisiensi tersebut selama kurun waktu penelitian rata-rata menunjukkan tingkat efisiensi yang belum efisien. Rata-rata skor efisiensi seluruh DMU secara teknik adalah $97.80 \%$, secara ekonomi sebesar $92.46 \%$, dan secara skala sebesar $94.5 \%$. Masih terdapat enam DMU yang tidak efisien secara teknik dan 17 DMU yang tidak efisien secara ekonomi dan skala dari 36 DMU yang dianalisis.

Sumber ketidakefisienan secara teknik dari variabel input dan output yang dimiliki perusahaan, sebagian besar disebabkan oleh variabel input pembayaran klaim dan variabel output dana tabarru'. Keduanya dapat diperbaiki dengan melakukan perbaikan proses underwriting. Jika dari sisi skala usaha, sumber ketidakefisienan perusahaan asuransi umum syariah disebabkan oleh rata-rata perusahaan asuransi umum syariah masih dalam bentuk Unit Usaha Syariah (UUS) dan jumlah pengguna asuransi syariah yang masih sedikit sehingga market share kontribusi bruto asuransi syariah khususnya asuransi umum syariah sangat rendah. Sumber ketidakefisienan secara teknik dan skala mendorong ketidakefisienan secara keseluruhan. Bagi perusahaan asuransi umum syariah yang belum mencapai efisiensi dapat meningkatkan efisiensinya dengan mengacu pada perusahaan asuransi umum syariah yang relatif efisien.

\section{Saran}

1. Bagi Regulator, diperlukan dukungan berbagai program pengembangan peraturan (regulasi), strategi, dan jaringan pengembangan serta program asuransi syariah untuk mendukung mencapaian efisiensi secara manajemen (teknik) dan skala. Kebijakan tersebut antara lain dapat berupa peningkatan sosialisasi 
pada masyarakat terkait asuransi syariah khususnya asuransi umum syariah untuk mendorong tingkat kesadaran berasuransi pada asuransi syariah sehingga mampu menambah jumlah pengguna asuransi syariah. Selain itu, untuk meningkatkan skala usaha asuransi umum syariah dapat dilakukan dengan pembentukan perusahaan full fledge syariah dari perusahaan unit usaha syariah.

Disisi instrumen investasi syariah juga perlu ditingkatkan, sebab dengan adanya variasi tempat investasi bagi perusahaan asuransi umum syariah maka akan mendorong perusahaan semakin produktif dalam mengelola dananya.

2. Bagi Perusahaan, diperlukan pengambilan kebijakan internal yang tepat untuk meningkatkan efisiensinya, antara lain dengan perbaikan proses underwriting, pengelolaan dana pada aset-aset yang lebih produktif, perbaikan pelayanan, perbaikan sumber daya insani perusahaan, pengelolaan beban-beban yang lebih baik, dan sebagainya untuk pencapaian efisiensi teknik atau murni. Selain itu, peningkatan skala usaha perlu dilakukan untuk meningkatkan market share melalui perluasan produk untuk memenuhi kebutuhan pasar dan meningkatkan kerjasama dengan perusahaan lain yang membutuhkan jasa asuransi.
3. Bagi peneliti yang ingin melakukan penelitian dengan tema yang sama di masa yang akan datang, hendaknya periode pengamatan diperpanjang serta menggunakan jumlah variabel yang lebih banyak terutama variabel untuk mengukur efisiensi dalam prespektif Islam sehingga dapat menghasilkan output yang lebih akurat.

\section{DAFTAR PUSTAKA}

Abdin Z, Endri. 2010. Kinerja efisiensi teknis bank pembangunan daerah: pendekatan data envelopment analysis (DEA). Jurnal Akuntansi dan Keuangan 11(1): 21-29

Asosiasi Asuransi Syariah Indonesia. 2014.

Data

Bisnis

2014.

http://www.aasi.or.id/ain/dta-bisnis-

2014, diakses pada tanggal 05 September 2016

Asosiasi Asuransi Syariah Indonesia. 2015.

Data Bisnis 2015.

http://www.aasi.or.id/main/dta-

bisnis-2015, diakses pada tanggal 05 September 2016

Benarda, Ujang Sumarwan, dan Muhamad Nadratuzzama Hosen. 2016. Tingkat Efisiensi Industri Asuransi Jiwa Syariah Menggunakan Pendekatan Two Stage Data Envelpoment Analysis. Jurnal Aplikasi Bisnis dan Manajemen, Vol.2 No.1. http://journal.ipb.ac.id/index.php/ja bm

Budi, Daniel Setyo. 2010. Efisiensi Relatif Puskesmas-Puskesmas di Kabupaten 
Pati Tahun 2009. Jakarta: Universitas Indonesia

Departemen Agama Republik Indonesia. 2005. Al-Qur'an Al Karim dan Terjemahannya. Semarang: PT Karya Toha Putra Semarang

Eling, Martin \& Wei Huang. 2011. An Efficiency Comparison of The Nonlife Insurance Industry in the BRIC Countries. Working Papers on Risk Management and Insurance No.94

Fatwa Dewan Syariah Nasional Majelis Ulama Indonesia Nomor 21/DSNMUI/X/2001 tentang Pedoman Umum Asuransi Syariah

Indrawati, Yuli. 2009. Analisis Efisiensi Bank Umum di Indonesia Periode 20042007: Aplikasi Metode DEA. Depok: Universitas Indonesia

Karim Consulting Indonesia. 2015. Islamic Finance Outlook 2015

Kristiyanto, Yahuda Eko. 2010. Pengukuran Tingkat Efisiensi Bank-Bank Umum di Indonesia (2000-2007): Aplikasi Data Envelopment Analysis (DEA) dan Tobit Analysis. Surabaya: Universitas Airlangga

Mala, Ainul. 2015. Evaluasi Efisiensi dan Faktor-Faktor yang Mempengaruhi Efisiensi Perusahaan Asuransi di Indonesia Periode 2008-2010. Surabaya: Universitas Airlangga

Muhammad. 2007. Lembaga Ekonomi Syari'ah. Yogyakarta: Graha IImu

Otoritas Jasa Keuangan (OJK). 2016. Daftar Perusahaan Asuransi Umum, Jiwa, dan Reasuransi dengan Prinsip Syariah 2016.:
http://www.ojk.go.id/id/DaftarPerusahaan-Asuransi-Umum-Jiwadan Reasuransi-dengan-PrinsipSyraiah, diakses pada Tanggal 05 September 2016

Republik Indonesia. Undang-Undang Nomor 40 Tahun 2014 Tentang Perasuransian

Rodoni, Ahmad. 2015. Asuransi dan Pegadaian Syariah. Jakarta: Mitra Wacana Media

Sari, Ditta Feicyllia. 2015. Analisis Efisiensi Pembiayaan Bank Umum Syariah dan Bank Umum Konvensional di Indonesia dengan Metode Data Envelopment Analysis (DEA). Surabaya: Universitas Airlangga

Shihab, M Quraish. 2009. Tafsir Al-Mishbah. Jakarta: Lentera Hati 